\title{
A ton for Thompson's tome
}

\author{
The centennial celebrations for morphology masterwork On Growth and Form are just kicking off. We \\ look at why physicists should get involved.
}

In 1917, Scottish biologist and mathematician D'Arcy Thompson laid out his conviction that growth and form in nature could be understood from physical and mathematical principles ${ }^{1}$. One hundred years on, On Growth and Form has garnered an impressive array of followers - Alan Turing, Jackson Pollock, Stephen Jay Gould and Mies van der Rohe counting in their number. And its impact on the worlds of cell and developmental biology is quite immeasurable. But in some ways its repercussions for physicists are only now emerging.

Thompson's book covers the gamut of biological phenomena, using examples of pattern formation in plants and animals to support the notion that physical mechanisms limit the growth and structure of organisms. Perhaps the most controversial - certainly the most provocative - is the chapter on transformations. In it, Thompson assembled evidence for geometrical mappings between the form of different species (see illustrations), which intimated that the laws of growth might trump those of evolution in explaining the way that related species differ.

Pre-eminent coral expert J. Arthur Thomson reviewed the volume for Nature in September 1917. Thomson was full of praise for the "masterly book", noting "what promise there is in the endeavour to carry into the study of living beings the laws and lessons of the inorganic"2. But his initial reaction to the work was made plain in the closing paragraph. "Magnificent," he said, "but not biology".

That his ultimate verdict was far more forgiving suggests a flexibility that may not have been shared by many at the time of publication. Certainly, biologists as a whole did not immediately take up the ideas presented in the book, although its inspirational value was acknowledged not long after $^{3}$. The consensus seemed to be that it was a beautiful, though not practical, work that strayed from mainstream biology into the realm of mathematics and physics.

Many in the physics world would say quite the opposite. Countless scientists retracing Thompson's footsteps along this interdisciplinary border will have heard the refrain: "That's not physics". But to paraphrase Thomson in his review for Nature: who knows better than the physicist what physics is and is not?

Historically, Nature Physics toed a conservative line, making clear the distinction between research that constitutes physics and work that simply uses physical concepts to divine understanding in other fields. And we seldom published the latter. But more recently you may have noticed that we've begun to relax this rule. The late, great Sir Sam Edwards is fondly remembered for his belief that "physics is what physicists do". We here at Nature Physics can find no better way to put it.
That's not to say that the journal will henceforth be a breeding ground for all interdisciplinary science - nor will it cease to be a welcome destination for the very best in everything from condensed-matter to high-energy physics and beyond. But we'd certainly like to see Thompson's successors share its pages.

This issue of Nature Physics is no exception. On page 380 , a study of the vortices created by larval starfish reveals 'eigenstrokes' that betray a trade-off between eating and swimming (see also News \& Views on page 326 ). And on page 408 , simulations of a chemically active droplet suggest a model for protocells - with profound implications for our understanding of the origin of life (see also News \& Views on page 323). Though this research may not follow directly from Thompson's musings, the interdisciplinary approach certainly echoes its spirit.

The centenary of the publication of On Growth and Form promises to be memorable, with a series of conferences, exhibitions and events in the works (www.ongrowthandform.org). We would urge you to join in the celebration, and take inspiration from D'Arcy Thompson's formidable legacy.

\footnotetext{
References

1. Thompson, D. W. On Growth and Form (Cambridge Univ. Press, 1917).

2. Thomson, J. A. Nature 100, 21-22 (1917).

3. Waddington, C. H. Nature 157, 87-88 (1946).
}

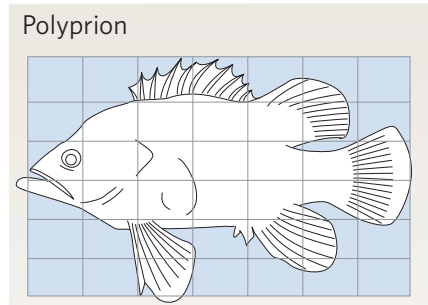

Pseudopriacanthus altus

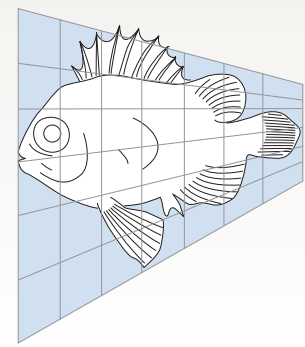

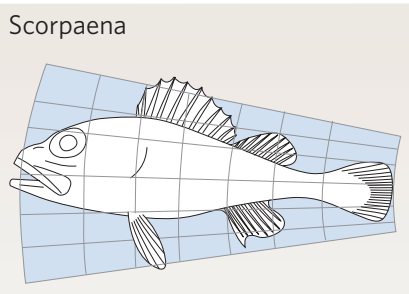

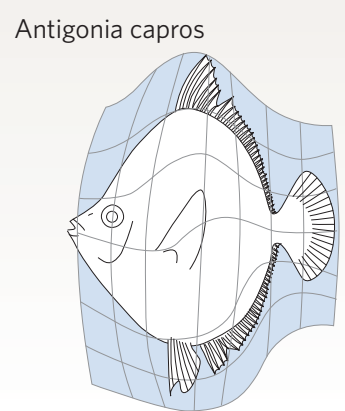

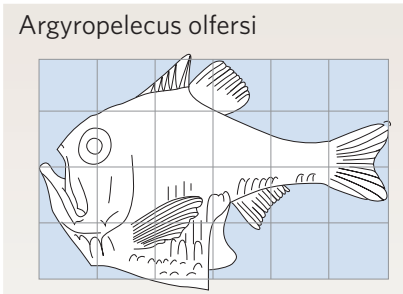

Sternoptyx diaphana

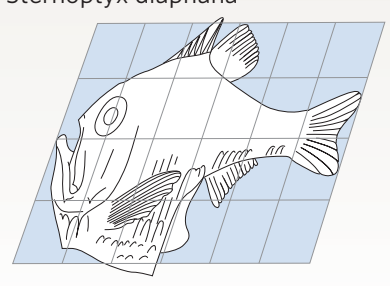

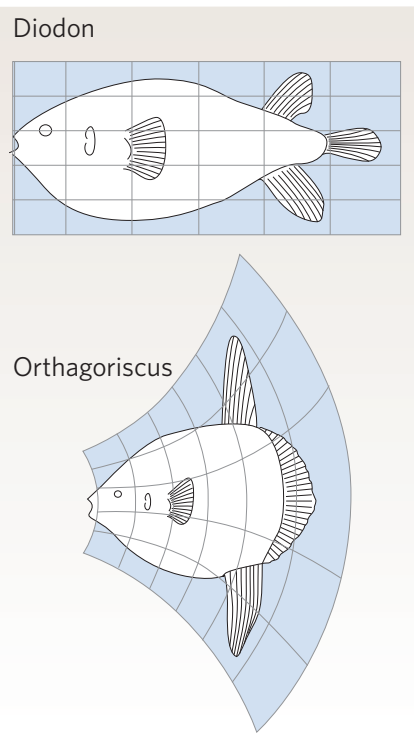

